\title{
O \\ OLHARES \\ Educação, tecnologias e covid-19: o que nos dizem os estudantes
}

\author{
Maria José Souza Pinho \\ Universidade do Estado da Bahia \\ m.jpinho@uneb.br \\ Kelly Meneses Fernandes \\ Universidade do Estado da Bahia \\ popovi12@gmail.com \\ Rafaela Rocha-Oliveira \\ Universidade do Estado da Bahia \\ rroliveira@uneb.br
}

\section{RESUMO}

Em meio a uma crise sanitária, sem precedente e derivada da contaminação do SARS-CoV2 , a educação vive também uma crise com estudantes e professores privados da experiência presencial de sala de aula. A preocupação com a interrupção parcial ou total das atividades nas escolas e universidades reafirma, mais uma vez, a importância da educação para o desenvolvimento da sociedade. Sendo assim, o objetivo deste estudo, foi analisar as narrativas dos estudantes de um curso de graduação para essa nova situação imposta, na perspectiva de visibilizar suas vozes, especificamente quanto à proposta de mediação tecnológica. A abordagem do estudo foi qualitativa e como instrumento de coleta de dados utilizou-se um questionário, com questões abertas, no Google Formulários. Os dados foram analisados à luz da Análise de Conteúdo, na qual chegamos às seguintes categorias, a) $\mathrm{O}$ vírus da mediação tecnológica; e b) Confinados..., e daí? As reflexões tecidas neste estudo mostram que esse assunto será recorrente por muito tempo, porque desafia nossas escolhas, nossos caminhos e nossos saberes. O distanciamento físico e a dificuldade de aceitação do "novo" modelo de aprendizagem para os estudantes são o reflexo da fragilidade enquanto humanos e enquanto sociedade na elaboração de políticas inclusivas quanto ao acesso à tecnologia na área educacional pública.

Palavras-chave: COVID-19; mediação tecnológica; ensino remoto.

\section{Education, tecnology and covid-19: what to say the students}

\section{ABSTRACT}

During an unprecedented health crisis resulting from the contamination of SARS-CoV-2, education is also experiencing a crisis with students and teachers being deprived of classroom experience. The concern with the partial or total interruption of activities in schools and universities reaffirms once again the importance of education for the development of society. Therefore, this study aimed to analyze the biology students' narratives for the new situation imposed in the perspective of making their voices visible, specifically regarding the technological mediation proposal. The study approach was qualitative and as a data collection instrument, a questionnaire was used, with open questions, in Google Forms. The data were analyzed in the light of Content Analysis, in which we arrived at the following categories, a) 
The virus of technological mediation; and b) Confined ..., so what? The reflections made here show that this subject will be recurring for a long time because it challenges our choices, our ways, and our knowledge. The physical distance and the difficulty of accepting the "new" learning model for students is a reflection of our fragility as humans and as a society in the development of inclusive policies regarding access to technology in the public educational.

Keywords: COVID-19; technological mediation; e-learning.

\section{Introdução}

Ao final de 2019, o planejamento do ano letivo de 2020 já estava preparado para acontecer dentro da "normalidade" e, de repente, com a pandemia da COVID-19 mudaramse os planos dos alunos, dos professores, da gestão, das aulas de campo, do encontro de estudos, da realização de pesquisas, dos estágios, das atividades extensionistas, do ir e vir, enfim, a universidade com o fechamento completo de sua estrutura física precisou se reinventar. Com a ausência de aulas presenciais, a universidade que já fazia uso dos Ambientes Virtuais de Aprendizagem (AVA) para cursos de extensão e pós-graduação na modalidade do Ensino a Distância (EaD) e de alguns meios digitais como projetos-piloto usando o Skype corporativo e, mais frequentemente, as videoconferências para reuniões, devido à característica multicampi da Universidade, ficou à deriva. Na graduação presencial utilizavam-se os aplicativos (Whatsapp) ou correio eletrônico para manter a comunicação para além do espaço físico, entretanto para realizar o processo de ensino e aprendizagem, a aula propriamente dita, contava-se com pouquíssimas experiências dos docentes usando espaços virtuais de aprendizagem, a exemplo do Google Classroom.

Ao decretar o fechamento das universidades e suspensão das aulas, priorizou-se o distanciamento social como condição sine qua non de prevenção à saúde e de proteção à vida. Embasados em recomendações dos órgãos nacionais e internacionais de saúde e de vigilância sanitária, essas medidas visavam à proteção de vidas com o objetivo de frear a rápida propagação da COVID-19. Evidências comprovam que o fechamento das escolas e das universidades, combinado com restrições de deslocamento, são medidas, não clínicas, muita efetivas para diminuir a curva de contágios, podendo reduzir o número de infecções acima de 92\% (PREM et al, 2020).

Em meio ao contexto político educacional atual, vivencia-se um momento de reflexão, incertezas, perdas de recursos, mudanças de políticas educacionais por meio de medidas provisórias que, sob a égide da pandemia, disfarçam o controle e a vigilância sobre as universidades. A valorização dos profissionais da educação, a infraestrutura das universidades e das escolas da educação básica, a implementação de programas, a exemplo do "Future-se" e Homeschooling, constituem-se como mecanismos excludentes e antidemocráticos (AGUIAR; AGUIAR, 2020) que foram agravados pelas questões da pandemia.

Essa situação de incerteza, de desconfiança e de emitir um prognóstico do comportamento da COVID-19, levou muitos educadores a buscarem uma solução, sendo necessário ouvir parte dos interessados no processo de ensino e aprendizagem: os discentes. Essa inquietação do momento deu margem à indagação de várias questões, dentre elas: Que desafios e dificuldades a mediação tecnológica ofereciam a esses alunos e alunas? Do que os estudantes necessitavam e do que sentiam falta no momento do 
distanciamento social e suspensão das atividades presenciais?

Sendo assim iniciou-se um processo investigativo com discentes, de um curso graduação de uma universidade pública do estado da Bahia, com o objetivo de analisar as narrativas dos estudantes para a nova situação imposta, especificamente quanto a proposta de mediação tecnológica no ensino e sua percepção da realidade para o "novo normal". Chamamos atenção que o termo "novo normal", não deve ser normalizado neste momento, porque compromete fortemente as condições de trabalho dos educadores, assim como as condições efetivas da aprendizagem dos discentes, resultando na precarização do trabalho docente (FERNANDES, 2020).

\section{Educação como bem de produção e não como bem de consumo}

Numa onda planetária, escolas e universidades foram fechadas. Professores e estudantes foram afetados pela crise sanitária desencadeada pela COVID-19 com medidas de isolamento social. Entretanto, como não "estamos no mesmo barco", professores e alunos foram afetados de modo diferente. A União das Nações Unidas (UNESCO) estima que 1,5 bilhão de estudantes foram afetados pela pandemia, primeiro com o cancelamento das aulas e depois com a mudança no formato de ensino (UNESCO, 2020). Exemplificamos aqui o caso da Espanha cujos gestores e professores recorreram a um plano $B$, num curto espaço de tempo, para ajustar-se ao que exigia o momento. As aulas dos ensinos básico e superior aconteceram via online, com medidas de assistência aos estudantes por meio de empréstimos de computadores ou auxílio financeiro emergencial e criação de um portal para professores, desenhado para oferecer recursos de orientação e formação no que se refere a metodologias online, além de atenção psicológica para docentes e discentes. Ainda assim, em documento elaborado pela Fundação para Inovação da Espanha indicava que "nenhum sistema educativo está preparado para universalizar em tempo recorde uma aprendizagem online eficaz que responda a uma situação como essa, e muito menos assegurando qualidade e equidade no processo" (ZUBILLAGA; GORTAZAR, 2020, p. 4).

Ou seja, o documento já sinalizava a dimensão social da pandemia e a cultura de privilégios que opera em benefícios de alguns grupos e impedem transformações estruturais e democráticas.

No Brasil, mais especificamente na região desta pesquisa, discentes não dispõem das mesmas medidas emergenciais oferecidas pelas escolas e universidades da Espanha. A maior parte dos professores também não possui a expertise necessária para o ensino remoto e as Secretarias de Educação (estaduais e municipais) não dispõem de plataforma e metodologia estabelecidas pela urgência na troca do modelo de ensino. Essa é a realidade em que nos encontramos. Uma enquete, realizada com professores desta universidade no início da pandemia, mostra que $37,1 \%$ dos docentes $(n=301)$ do universo de 812 respondentes, não sabem utilizar a interface do Ambiente Virtual de Aprendizagem (AVA) e 62\% ( $n=510)$ nunca participou de curso de formação voltado para mediação tecnológica ${ }^{1}$. Ou seja, a pandemia afetou a saúde, a economia e bruscamente a educação.

\footnotetext{
${ }^{1}$ http://www.sisform.uneb.br
} 
Nesse período de excepcionalidade, com relação à educação, as consequências iniciais foram as modificações no calendário letivo, interrompido ou não iniciado, e em seguida por escolas que aderiram ao trabalho remoto, à excessiva carga de trabalho de professores, à alteração na rotina das famílias, entre outras mudanças.

A situação da precarização do trabalho docente, por si só, gera uma sobrecarga de atividades e, não à toa, é perceptível o adoecimento de muitos profissionais da educação. Com o isolamento social e a suspensão das aulas, há uma pressão, principalmente por parte do governo federal, para que os docentes mantenham suas atividades profissionais de forma remota. Contudo, além da insegurança para atuar no ambiente online, o tempo de planejamento do professor aliado ao tempo de preparação de um material digital é muito maior e, portanto, tem causado uma sobrecarga do trabalho docente (HONORATO; MARCELINO, 2020). Claro que dependendo da forma que a proposta de ensino remoto está sendo entendida pela escola e pelas secretarias de educação, essa sobrecarga pode ser maior ou menor. Levando em consideração a desigualdade de gênero, exposta de maneira mais incisiva na pandemia, mulheres que estão em situações de trabalho remoto, se veem sobrecarregadas, principalmente quando as suas rotinas de trabalho são somadas aos cuidados com os filhos e às tarefas domésticas, funções ainda atreladas, majoritariamente, ao universo feminino.

Para além de toda estrutura necessária, há de se pensar qual a real necessidade ou para quem realmente é útil a imposição do ensino remoto. Será que essa modalidade de ensino garante uma educação emancipatória ou tem como base a educação bancária dentro dos modelos tecnicistas? Apesar da evidente relevância das Tecnologias de Informação e Comunicação (TIC) para a educação, o ensino remoto pensado de forma aligeirada e excludente possibilita um ambiente de aprendizagem? Assim, a proposta de ensino emergencial tem feito parte das constantes discussões online dos profissionais da educação (COLEMARX, 2020), no sentido de indicar toda a precarização da educação.

O desmantelamento da educação encontra na pandemia uma saída perfeita para materializar-se (CARA, 2020; REIS, 2020). A primeira medida provisória do dia $1^{\circ}$ de abril de 2020, desobriga o cumprimento de 200 dias letivos, entretanto mantém em 800h a carga horária mínima anual. Isso significa dizer que as escolas da educação básica devem propor soluções que passem por uma dessas vertentes: ampliação da educação de tempo integral, atividades complementares, conclusão do ano letivo em 2021 e ensino a distância. A opção do ensino a distância é considerada inviável, principalmente se for pensada sem iniciativas públicas que deem conta da exclusão social que ainda é prevalente para grande parte de estudantes das escolas públicas. A modalidade EaD, já regulamentada, foi alterada em 2017, permitindo ser oferecida também no ensino básico, entretanto possui características específicas que necessitam de infraestrutura e de métodos adequados, por parte das universidades, para sua implementação.

O Secretário de Educação do Estado da Bahia homologou a resolução n 27/2020 que trata das diretrizes para regulamentar as atividades curriculares domiciliares para a rede de educação básica e para instituições de ensino superior, reconhecendo a situação de emergência em saúde pública de caráter internacional em seu artigo $2^{\circ}$, indicando as múltiplas possibilidades de suporte digital e não digital (BAHIA, 2020).

Essa resolução não recomenda a substituição do ensino presencial pelo Ensino a 
Distância (EaD) no formato institucional e destaca as cotas já anteriormente descritas em leis para sua aplicação. Nas Instituições de Ensino Superior (IES), a cota estipulada fica em torno de $40 \%$ de carga horária do currículo para modalidade EaD, já previstas em lei anteriormente, e sugere ações das IES que fortaleçam a mediação tecnológica com uso de mídias e de plataformas para atividades domiciliares.

O que eles esqueceram é que, assim como os estudantes da educação básica, muitos discentes universitários também não têm acesso às tecnologias de forma ampla. Parece desconhecer a realidade de estudantes que moram na zona rural que, em virtude do fechamento das universidades, retornaram à casa de seus pais, localizadas fora da "cidade grande", geralmente, onde ficam os campi universitários desta instituição.

O Colemarx (2020, p.9) alerta sobre a intencionalidade de organismos internacionais "se aproveitarem da pandemia para fazer marketing e vender serviços". De acordo com o estudo citado, mais de 20 estados brasileiros já fizeram parceria com a Plataforma Rede Escola Digital que é financiada pelas mesmas organizações e grupos empresariais que participaram da elaboração da controversa Base Nacional Comum Curricular (BNCC).

Corroboramos com Nicodemos (2020) e Aguiar; Aguiar (2020) sobre a atual política macro de desescolarização e para falar em termos atuais seria uma "uberização" do ensino na formação do sujeito neoliberal. Socialmente falando, os efeitos da pandemia têm um recorte de classe, de raça e de gênero. As classes subalternas sofrerão muito mais. Não estamos no mesmo barco, talvez no mesmo mar revolto cada um com uma embarcação diferente, umas mais resistentes, outras mais frágeis (MARTINS, 2020).

\section{Metodologia}

Pensando nesse cenário, o Laboratório Interdisciplinar de Pesquisa, Ensino e Extensão em Biologia - LIPEEBIO buscou uma escuta sensível sobre o que os/as alunos/as de um curso de Licenciatura diziam sobre as questões em pauta, no mar de discussões sobre a COVID-19, Mediação Tecnológica e Educação.

Para isso elaborou-se um questionário usando a plataforma Google Formulários que foi enviado dia 16 de abril de 2020, via correio eletrônico e grupos de Whatsapp, para 110 estudantes matriculados no semestre 2020.1. O questionário contém seis questões discursivas (Quadro 01) e sem prazo para devolutiva e continua válido até o momento. A identidade dos participantes da pesquisa foi preservada por questões éticas e os estudantes foram identificados por letras maiúsculas do alfabeto $(A, B, C, \ldots, V)$. $O$ fato desta pesquisa obter apenas 22 devolutivas pode ser considerado um dado relevante num contexto de pandemia e distanciamento, uma vez que $80 \%$ dos estudantes não se mostraram dispostos a responder. Portanto dar voz a uma amostra tão pequena reflete parte do problema abordado no estudo em questão.

Quadro 1 - Lista de perguntas do instrumento de pesquisa.

\begin{tabular}{|c|l|}
\hline QUESTÃO & \multicolumn{1}{|c|}{ ENUNCIADO } \\
\hline 01 & $\begin{array}{l}\text { Qual(is) desafio(s) à mediação tecnológica digital pode trazer para você, seus colegas e sua } \\
\text { família nesse momento? }\end{array}$ \\
\hline 02 & $\begin{array}{l}\text { Para você, quais seriam as ferramentas tecnológicas que poderiam ajudar nesse sentido? E } \\
\text { por quê? }\end{array}$ \\
\hline
\end{tabular}




\begin{tabular}{|l|l|}
\hline 03 & Que dificuldades você tem em relação às ferramentas tecnológicas? \\
\hline 04 & Que soluções você propõe? \\
\hline 05 & Do que sente falta neste momento, pensando em seu percurso formativo? \\
\hline 06 & O que mais você precisa agora? \\
\hline
\end{tabular}

Fonte: Dados da pesquisa, 2020.

As respostas dos participantes foram analisadas com base na metodologia de Análise do Conteúdo. De acordo com Bardin (2016), podemos afirmar que essa metodologia tem como objetivo superar a visão simplória dos acontecimentos sociais e, ao mesmo tempo, manter um rigor sistemático em sua análise. Dessa forma, após a "leitura flutuante", as categorias foram criadas de acordo com as questões propostas e os elementos que mais se repetiam nas narrações dos estudantes. De acordo com Bardin (2016, p. 149) elas são "uma representação simplificada dos dados brutos.". Assim, deste estudo emergiram duas categorias: a) O vírus da mediação tecnológica; e b) Confinados..., e daí?

A primeira categoria faz alusão ao uso de um "elemento intruso" que surgiu no processo educacional e desestabiliza-o, tomando como base as respostas das questões de 01 a 04 , que buscou reunir o que os estudantes revelaram, proporcionando reflexões principalmente em torno da viabilidade e dos desafios de um ensino remoto, considerando as especificidades de uma parcela estudantil com baixo, ou sem acesso à internet de qualidade. $A$ análise das respostas obtidas para as questões 05 e 06 possibilitaram a construção da segunda categoria, fazendo uma crítica ao desdém de algumas autoridades brasileiras. Destaca-se nela, como ponto de convergência, as reflexões sobre a importância da presencialidade, possível criadora de laços entre os sujeitos, bem como o sentimento que está potencializado, levando em consideração este contexto de acirramento das diferentes desigualdades existentes na sociedade.

Já existe uma ampla discussão sobre a qualidade do Ensino a distância (EaD) em detrimento ao ensino presencial e envolve questões que vão desde a importância das relações humanas no processo de aprendizagem até o acompanhamento avaliativo do estudante. É importante evidenciar que um dos propósitos iniciais do EaD foi a democratização da formação inicial. Como exemplo, podemos citar o Sistema Universidade Aberta do Brasil - UAB que foi instituído no ano de 2006, com o objetivo de expandir e de interiorizar a oferta de cursos e programas de educação superior no país e com uma dose substancial das tecnologias digitais.

Entre um modelo e outro, caracterizados por escalas de gradação das relações sincrônicas por meio das tecnologias digitais, destaca-se o ensino híbrido como uma intersecção entre os dois modelos. Não é uma modalidade nova, mas equilibra e intercala o uso das tecnologias no sentido de mediar o processo educativo.

No atual contexto de pandemia, o ensino remoto emergencial aparece transitando entre o EaD e o ensino híbrido, com uso largo de artefatos tecnológicos, mostrando-se uma importante ferramenta para manter o contato e o vínculo com os estudantes. Entretanto adotar esse modelo conduz a uma discussão que surge nas regiões do Brasil mais afetadas por políticas públicas inadequadas com vistas a superar as desigualdades no acesso aos bens e serviços, como no caso do semiárido baiano, que é a dificuldade/impossibilidade de acesso dos alunos à internet.

Como diz Žižek (2020, p. 204), "[...] a epidemia de Coronavírus em si não é claramente 
apenas um fenômeno biológico que afetou os seres humanos [...]", pois nos faz refletir que sua disseminação se relaciona, por exemplo, com a cultura (hábitos alimentares), com a economia global e local, bem como a forma como fazemos educação. É um desafio que reorienta as condições do viver em todos os seus sentidos.

\section{Resultados e Discussão}

As categorias emergiram das respostas obtidas e são uma mistura de forma e conteúdo. Ou seja, ao mesmo tempo os/as discentes, elencaram que para ocorrer o processo de mediação no processo de aprendizagem, é necessário um aparato tecnológico básico nesse processo: acesso à internet. Mesmo quando não tínhamos datashow para as "novas" aulas, recorríamos ao bom e velho quadro branco. Evidentemente, agora não podemos contar com um plano alternativo que dispense o uso da internet.

\section{O vírus da mediação tecnológica}

Na pesquisa realizada, 11 estudantes (46\%) sinalizaram que o maior desafio com a mediação tecnológica é o acesso à internet (Figura 1). Esse desafio também pode ser um dos motivos relacionado ao baixo número de devolutiva dos questionários. Como grande parte dos alunos retornou a zona rural, local de residência da família, por conta do fechamento da universidade, muitos ficaram sem acesso à internet de qualidade ou sem acesso nenhum, portanto poderiam não ter meios de responder ao questionário online enviado, justificando assim o baixo retorno do instrumento da pesquisa.

Figura 1 - Desafios diante da mediação tecnológica.

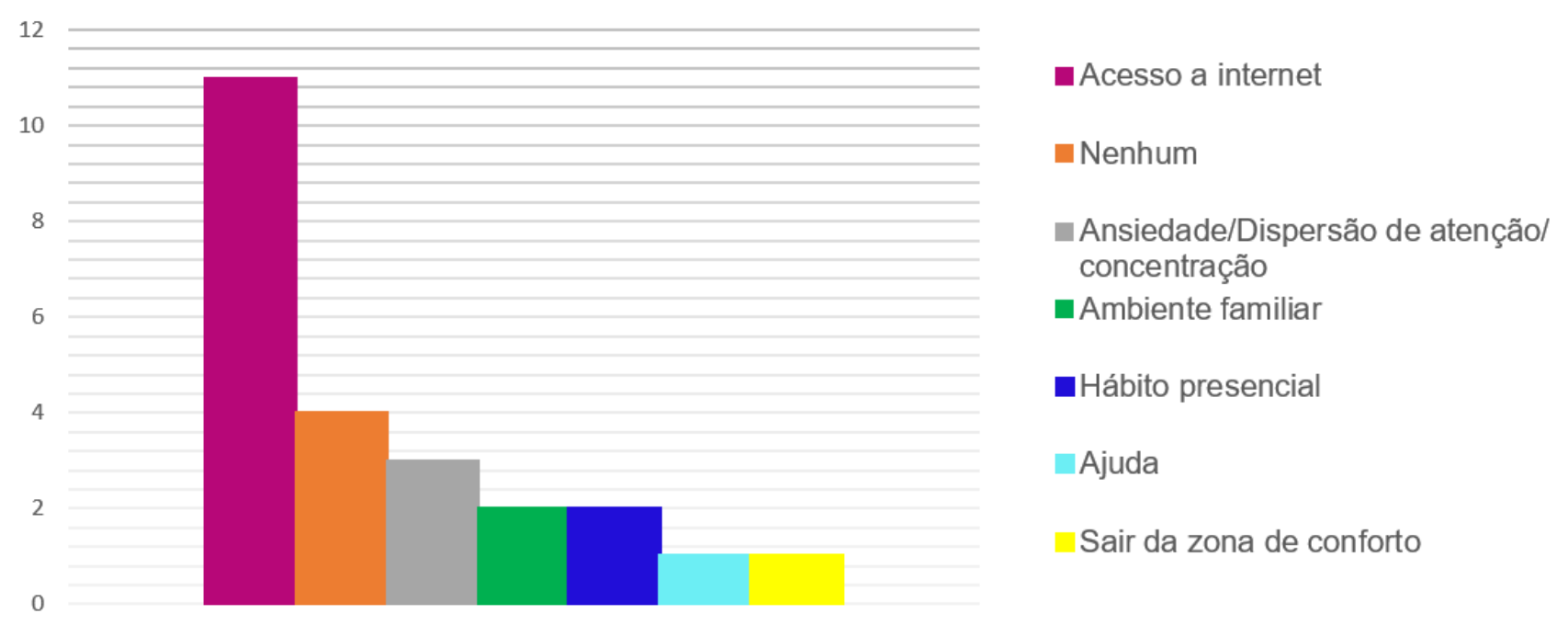

Fonte: Dados da pesquisa, 2020.

Corroboramos com o Colemarx (2020, p. 8) que "[...] no século XXI, o acesso à internet é um direito fundamental, a exemplo dos direitos, ainda não assegurados, à água potável, à rede de esgoto, à energia, ao transporte.”. Inclusive, não é raro, algumas propriedades rurais não terem acesso à energia, o que também impossibilitaria o acesso à internet. Não ter acesso e equipamentos necessários aprofunda muito mais as desigualdades e precisamos as desigualdades a partir do uso da internet.

Santos e Pellanda (2020) apontam, com base na Pesquisa Por Amostra Domiciliar 
Contínua (PNAC), que, em 2017, "[...] nenhuma unidade federada chega a $80 \%$ de acesso com conexão em banda larga e mais da metade delas não chega sequer a $60 \%$ com esse tipo de conexão". Na Bahia, apenas $35 \%$ dos domicílios possuem computador ou tablet e apenas $31 \%$ possuem computador ou tablet com banda larga. $\mathrm{O}$ acesso dos estudantes do ensino médio à internet era em torno de $83 \%$, mas isso não garante que o pacote de dados utilizado dê conta de realizar todas as atividades. Esse relatório não apresenta dados sobre estudantes universitários especificamente, mas por faixa etária. Em 2018, esse mesmo relatório apontou que $71 \%$ dos domicílios, na Bahia, possuíam acesso à internet e que o aparelho móvel é responsável por 57,6\% nesse tipo de acesso (SANTOS; PELLANDA, 2020). No entanto, mesmo com esse aumento percentual, faltariam identificarmos se esses domicílios estão em centros urbanos ou zonas rurais.

É fato que boa parte dos alunos e das famílias não possuem equipamento nem conectividade e essas enquetes apontam a brecha digital que ainda permeia a sociedade. Pesquisadores da Organização para a Cooperação e Desenvolvimento Econômico-OCDE advertem que a brecha digital vai muito mais além do ter acesso às tecnologias e se baseia nas condições socioeconômicas de cada família. A segunda brecha seria o desenvolvimento de habilidades e competências construídas a partir de seu uso, ou seja, o tempo de uso e a qualidade desse uso. A terceira brecha se relaciona à aplicabilidade dessa tecnologia pelos professores com a disponibilidade de recursos em plataformas online de apoio ao ensino (ZUBILLAGA; GORTAZAR, 2020). Entendemos que essa é uma habilidade a ser construída também na formação de professores. Temos, então, uma brecha digital, social e educativa que se retroalimenta. A COVID-19 ainda não conseguiu alterar as estruturas econômicas, políticas e sociais que geram exclusão dos mais vulneráveis.

Outro desafio apontado pelos estudantes para participação de aulas remotas é a dificuldade de atenção/concentração durante esse período de pandemia e de isolamento social. Essa dificuldade pode estar relacionada às incertezas advindas da crise gerada pelo momento pandêmico, bem como pelas dificuldades socioeconômicas vivenciadas. Segundo o IBGE, a Bahia apresenta a maior taxa de desemprego no país no primeiro trimestre de 2020, com o agravamento do número de pessoas com a COVID-19 e o fechamento de muitos centros comerciais da Bahia, essa taxa pode estar ainda maior e muitos discentes estão ajudando os pais na "roça2" ou até mesmo buscando empregos no mercado de trabalho.

O enfrentamento à pandemia vem carregado de uma preocupação com a saúde e com a sobrevivência de uma parcela da sociedade que se constitui a mais vulnerável nesse momento: a classe trabalhadora, periférica, pobre, rural e negra. Para Maraux e Marmori (2020), "A adoção da mediação tecnológica deve vir acompanhada com a construção de redes e conexões que nos aproxime" e não nos afaste.

De acordo com as narrativas dos estudantes, outro desafio que a mediação tecnológica poderia trazer é lidar com os estudos em meio ao "novo" ambiente familiar. Como já mencionado, o isolamento social e o fechamento das escolas e das universidades criaram novas configurações de habitação familiar: filhos/as que voltaram para casa dos pais; e pais que ficam um tempo muito maior com seus companheiros e/ou filhos/as. Dentro dessa nova

\footnotetext{
${ }^{2}$ Palavra utilizada no nordeste brasileiro e tem se refere a campo.
} 
realidade, podemos identificar no relato do estudante $B$ a crença de que o ensino remoto pode prejudicar seu desempenho acadêmico, por conta da situação do ambiente familiar durante o isolamento social: "Limitar minha situação familiar (muitas pessoas em uma casa, causar barulho, etc.), o meu desempenho no estudo pode ser prejudicado por meio da utilização da mediação tecnológica (estudante B).

Além do maior do número de membros da família em casa ao mesmo tempo, o distanciamento social também intensificou um lamentável dado de aumento de casos de violência doméstica em todo o mundo. As principais vítimas são as mulheres, crianças e adolescentes considerados os grupos mais vulneráveis em nossa sociedade machista e patriarcal (MARQUES et al, 2020). Ainda de acordo com as autoras, (p.2) "A convivência ao longo de todo o dia, especialmente entre famílias de baixa renda vivendo em domicílios de poucos cômodos e grande aglomeração, reduzem a possibilidade de denúncia com segurança [...]", o que indica que situação de violência familiar no Brasil deve ser muito maior do que os dados sobre as denúncias indicam. Apesar de não ser uma realidade de todos/as, como esperar comprometimento dos estudantes no processo de aprendizagem já que muitos vivenciam essas situações? Qual o sentido do ensino remoto para esses estudantes que podem ser vítimas ou presenciar abusos dos familiares?

A realidade vivenciada nos convida a não aceitar o ensino remoto, como meio de exclusão, contudo a situação pandêmica nos permite flexibilizar o uso do ensino remoto sob a vigilância de não haver perdas aos estudantes que não podem fazer parte desse processo. É preciso entender o ensino remoto como temporário, não normal e não abrir mão da defesa da educação pública, presencial, laica e inclusiva. O que é possível ensinar e aprender nesse "novo normal"? Os professores tiveram tempo de entender e sentir o isolamento social? Ou isso foi imposto? As instituições se preocupam com os novos instrumentos de trabalho do professor? Como manter a saúde mental no meio de tanta pressão para ensinar e produzir conhecimento?

Para os estudantes, as duas maiores dificuldades (Figura 2) na adoção do modelo de mediação tecnológica seriam: o manuseio das ferramentas digitais, indicado por 7 estudantes (35\%) e o acesso/qualidade da internet, indicado por 6 deles (30\%). Apenas quatro estudantes indicaram que não teriam nenhuma dificuldade. O ensino remoto, a educação a distância e ensino híbrido são modalidades desconhecidas desses estudantes de graduação e para muitos professores também, do ponto de vista da usabilidade, conforme pesquisa já anteriormente mencionada. 


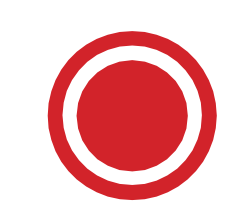

Figura 2 - Dificuldades para mediação tecnológica.

8
7
6
5
4
3

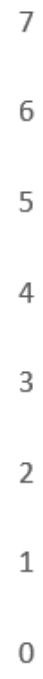

7
6
5
4
3
2
1
0

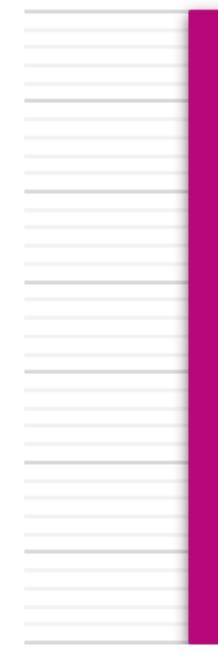

Dificuldade no manuseio

Acesso a internet /internet de qualidade

Nenhuma dificuldade

Financeira

Espaço no dispositivo

Então, quando eles indicam que teriam dificuldades com as ferramentas digitais é porque, de forma abrupta, os estudantes se viram obrigados a pensar em sua aprendizagem por meio de dispositivos eletrônicos como celulares, tablets, computadores ou notebooks como se fossem alunos da modalidade de ensino online e acostumados com webconferências, fóruns, chats, plataformas e-learning, wikis, podcasts, entre outros e ao mesmo tempo pensar como preservar suas vidas.

O discente necessitará ir além do conceito de inclusão digital ou da habilidade com computadores, "[...] precisará de inclusão cibercultural capaz de prepará-lo para fazer mais do que meramente subutilizar as potencialidades da web 2.0 e da mobilidade ubíqua" (SANTOS, 2019, p. 45). Como diz Santos (2019), há um deslocamento do mundo analógico para o mundo online e pressupõe habilidades com outras linguagens, as quais esses estudantes não estavam acostumados.

Eles, e muitos dos docentes, não foram educados digitalmente para essa mudança brusca, para entenderem esses espaços online como potencializadores de convergência e bricolagem de conhecimento coletivo, necessitam um tempo para transição do presencial para o virtual. Todos os alunos e alunas usam esses dispositivos no cotidiano (no mínimo o celular), entretanto quando se trata de aprendizagem exclusivamente por mediação tecnológica, necessita de uma reorganização na cognição da aprendizagem, pois agora o espaço não é mais físico, está nas "nuvens". Essa desigualdade tecnológica acaba por gerar também a desigualdade epistemológica, implica uma mudança cultural que é desafiante para a maioria deles. A COVID-19 não converte a sociedade em cidadão digital. As referências sobre cidadania digital consideram que a internet é um bem comum e um bem global de todos e todas. Isso implica não deixar ninguém para trás. E quando há pessoas que não se beneficiam desse bem comum, dizemos que há uma brecha digital, ocasionados pela ausência da alfabetização digital (OLMO, 2020).

$O$ acesso à internet e internet de qualidade são novamente destacados pelos estudantes como motivos de preocupação. Entendemos que o acesso universal à internet é um direito dos cidadãos e deve ser entendido como uma política pública e não apenas como 
uma prestação de serviço. O acesso à internet nunca foi tão imprescindível como agora, neste sentido a pandemia aprofunda ainda mais as desigualdades sociais e evidencia as fragilidades na nossa sociedade e nos sistemas públicos educativos (OLIVEIRA, 2020). Escolas e universidades, alunos e professores não passarão impunes a essa experiência de estarmos meses sem aula presencial. Como assevera Franco et al(2020), é precário o acesso à internet por grande parte da população brasileira e quando o faz, por meio de celulares, compartilham pacote de dados limitados para a família, influenciando a qualidade pedagógica das atividades com base no ensino remoto.

\section{Confinados... E daí?}

A segunda categoria de análise é um convite à reflexão sobre as relações entre tecnologia, educação e vínculos derivadas da presencialidade. Diferentes estudantes expressaram e revelaram aquilo que é fundamental ao processo de uma aprendizagem voltada para uma ética comunitária e que a tecnologia e o ensino a distância podem não resolver: a questão da presença. Em meio a esse mundo em estado de exceção, vale chamar a atenção que educação e aprendizagem se relacionam com existência, estar disponível para escutar e construir diálogos com os outros, enfim, ser sensível à existência dos outros. A manutenção desses vínculos da existência "[...] é precioso para a formação humana em nossa sociedade" (FRANCO et al, 2020, p. 2).

Alguns estudos (WANG et al., 2020; MAIA; DIAS, 2020) apontam alterações comportamentais (ansiedade, depressão e estresse) em estudantes universitários no primeiro momento de isolamento social com a suspensão das atividades acadêmicas, que podem ter sido geradas pela ausência do apoio social recebido, desencadeados pela mudança brusca da adaptação ao novo modo de viver. A dificuldade de adaptação pode gerar efeitos emocionais diferenciados que se relacionam ao modo como as pessoas enxergam essa nova experiência existencial. Quais as implicações negativas e positivas dessa circunstância? Em curto prazo é perceptível alterações físicas e emocionais (MAIA; DIAS, 2020), mas, a longo prazo, não há um consenso desses efeitos.

A presencialidade é uma constante na escolarização desses sujeitos (6 alunos) e citada como um fator importante no percurso acadêmico (Figura 3). O fluxo de informação, as formas de apreensão dos conteúdos, os modos de entendimento daquilo que circula no espaço acadêmico e na sala de aula se desloca para longe do olhar do aluno (GOUVÊA; OLIVEIRA, 2006). A falta da socialização é o que está por detrás da narrativa sobre o sentimento de falta das aulas presenciais, pois as necessidades afetivas e intelectuais para os discentes não seriam satisfeitas pelo modelo de ensino remoto. 


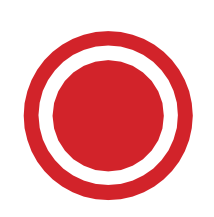

Figura 3 - Minhas ausências.

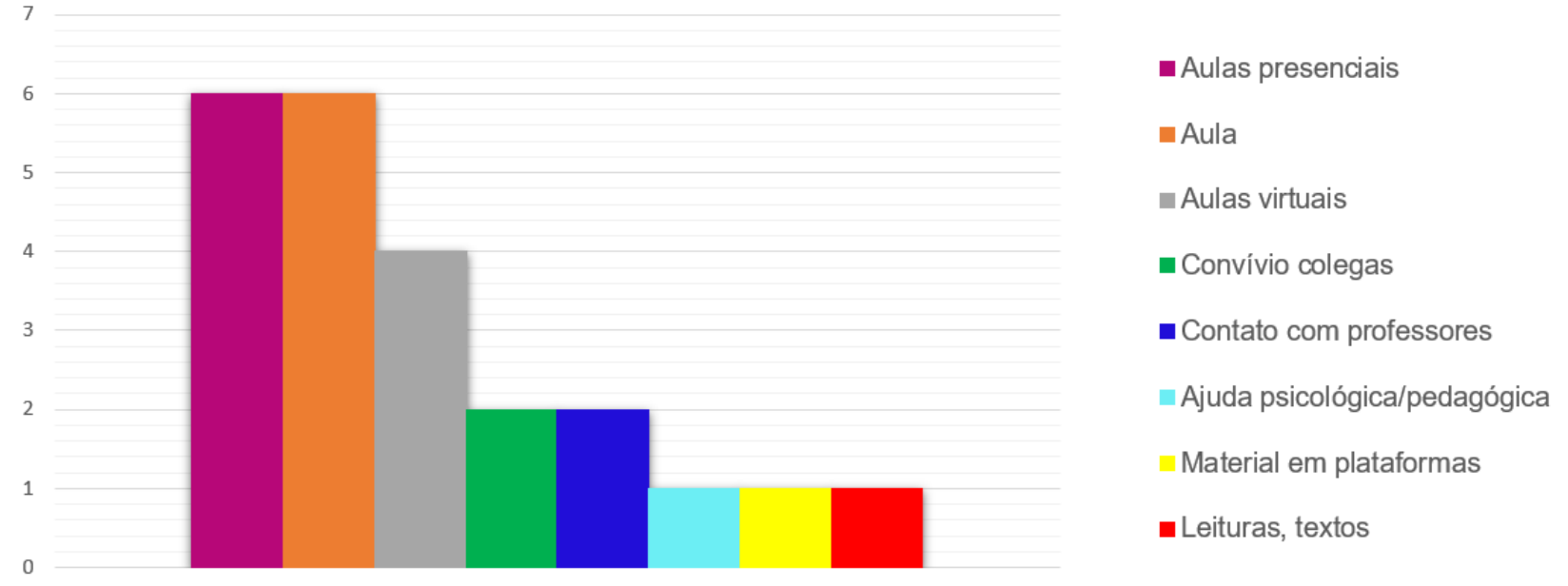

Fonte: Dados da pesquisa, 2020.

Os dados indicam a vontade dos estudantes pelo retorno a uma rotina de aulas e estudos, porém grande parte apontou como possíveis dificuldades: o acesso à internet e o manuseio das tecnologias. É possível pensar um projeto de retomada das aulas que deixe transparecer a precariedade de uma parte das pessoas envolvidas: professores e/ou estudantes? Havendo o retorno, nossas aulas partirão de qual lógica de aprendizagem?

Precisamos compreender que, se por um lado, é importante pensarmos em democratização das tecnologias, por outro, é fundamental questionar: como podemos utilizar as tecnologias não como meio de suprir a falta de aulas presenciais, e muito menos de reproduzir o mundo anterior em ruínas, mas como meio de aprendizagem daquilo que é importante para nosso viver coletivo?

A professora Edméa Santos (2003, p. 3) ao discutir as potencialidades do ambiente virtual de aprendizagem, considera aprendizagem como: "[...] um processo sócio-técnico onde os sujeitos interagem na e pela cultura sendo esta um campo de luta, poder, diferença e significação, espaço para construção de saberes e conhecimento". Entendemos que um processo de retomada de aulas mediadas por tecnologias, de maneira geral, exigirá de nós uma reflexão sobre os espaços que serão criados, a fim de potencializar a produção de conhecimento em disputa com nossas concepções sobre relações de poder, conhecimento, educação e currículo.

Diante das incertezas e das discussões que vem acontecendo sobre os rumos da educação nas universidades, neste momento de impacto da Covid-19, expressamos nossas preocupações em vistas das marcas possíveis para o bem e para o mal do tão falado ensino remoto:

Para o bem porque, em muitos casos, permite encontros afetuosos e boas dinâmicas
curriculares emergem em alguns espaços, rotinas de estudo e encontros com a turma
são garantidos no contexto da pandemia. Para o mal porque repetem modelos
massivos e subutilizam os potenciais da cibercultura na educação, causando tédio,
desânimo e muita exaustão física e mental de professores e alunos. Adoecimentos
físicos e mentais já são relatados em rede. Além de causar traumas e reatividade a
qualquer educação mediada por tecnologias. (SANTOS, 2020, p. 1).

Reconhecemos que no contexto de discursos governamentais que visam à precarização da educação pública e à disposição em acirrar a exclusão e as desigualdades 
nas universidades, é fundamental que busquemos aprofundar sobre os usos das tecnologias, assim como de que lógicas nos referimos para a partir de como vemos o mundo, assumir nosso compromisso com processos de aprendizagem e currículos capazes de articular comunicação dos conhecimentos que atravessam nossas vidas e a dos estudantes.

\section{Considerações Finais}

A modo de conclusão, as reflexões evidenciadas até aqui expõem que a crise da COVID-19 não é responsável pelas mazelas educacionais e políticas que reduzem o financiamento e investimento na área das ciências humanas que estamos vivenciando, porém é um sinal para despertar e empreender esforços no sentido de transformação da realidade das universidades, da educação e da sociedade. As relações foram modificadas e do mesmo modo as interações no processo ensino e aprendizagem. Evidenciou e aprofundou a distância que existe entre pobres e ricos, negros e brancos, cidade e campo, no que tange a investimentos na área educacional e tecnológica. O momento é ímpar, especial e urge a coletividade em busca de reunir as melhores saídas. Os discentes desse curso, tanto os que responderam ao questionário quanto os que não responderam, deixaram claro as dificuldades, os medos e os desafios diante da insegurança no processo de ensino e aprendizagem com as tecnologias de ensino propostas neste momento. Assim, o que estamos experimentando emergencialmente pode-se constituir em novas práticas de atenção a esse aluno e aluna na perspectiva de formação humana.

\section{Referências}

AGUIAR, Gilvânia Queiroz Madeira de; AGUIAR, Christiano Roberto Lima de. Políticas Educacionais numa perspectiva neoliberal:uma análise crítica da proposta para o Programa Future-se. Movimento-Revista de educação. v.7.n.13, 2020. DOI:

https://doi.org/10.22409/mov.v7i13.41418.

BAHIA. Conselho Estadual de Educação da Bahia. Resolução CEE N. ${ }^{\circ}$ 27, de 25 de março de 2020. Salvador, 2020.

BARDIN, Laurence. Análise de conteúdo. São Paulo: Edições 70, 2016.

CARA, Daniel. Agora é a hora da educação em tempos de pandemia. Canal do Jornalistas Livres no Youtube. Disponível em:

<https://www.youtube.com/watch?v=erWjp6a46ow\&t=1618s >. Acesso em: 20 mai. 2020. COLEMARX. Em defesa da educação pública comprometida com a igualdade social: porque os trabalhadores não devem aceitar aulas remotas. Coletivo de Estudos em Marxismo e Educação: Rio de Janeiro, 2020.

FERNANDES, Mariana. $2^{\circ}$ encontro - Planejamento e (re)organização pedagógica no ensino mediado por tecnologias. Canal do Prática Docente no Youtube. Disponível em : <https://www.youtube.com/watch?v=N8jl7HcwUWs $>$. Acesso em: 13 jul. 2020.

FRANCO, Adriana de Fátima el al. Ponderações sobre o ensino escolar em tempos de quarentena: carta às professoras e professores brasileiros. Disponível em:

<http://cev.org.br/biblioteca/ponderacoessobreoensinoescolaremtemposdequarentenacartaasprofessoraseprofessores-brasileiros/>. Acesso em: 28 abr. 2020.

GOUVÊA, Guaracira; OLIVEIRA, Carmen Irene. Educação a distância na formação de 
professores: viabilidades, potencialidades e limites. Rio de Janeiro: Vieira \& Lent, 2006. HONORATO, Hércules Guimarães; MARCELINO, Aracy Cristina Kenupp Bastos. A arte de ensinar e a pandemia do COVID-19: a visão dos professores. Revista Diálogos em Educação, v. 1, n. 1, 2020, p. 208 - 220. Disponível em:

<http://www.faculdadeanicuns.edu.br/ojs/index.php/1revistadialogosemeducacao1/article/vie w/39 >. Acesso em: 04 ago. 2020.

MAIA, Berta Rodrigues; DIAS, Paulo Cesar. Ansiedade, depressão e estresse em estudantes universitários: o impacto da COVID-19. Estudos de Psicologia. Campinas, 37, 2020. DOI: http://dx.doi.org/10.1590/1982-0275202037200067.

MARAUX, Amélia; MARMORI, Adriana. Nas encruzilhadas da ciência, da política e da vida. A TARDE, Salvador -Ba. 29/04/2020.

MARQUES, Emanuele Souza et al. A violência contra mulheres, crianças e adolescentes em tempos de pandemia pela COVID-19: panorama, motivações e formas de enfrentamento. Cad. Saúde Pública, v. 36, n. 4, 2020, p. 1 - 6. Disponível em:<https://doi.org/10.1590/0102-311X00074420>. Acesso em: 4 ago. 2020.

MARTINS, Marcos Francisco. Pensando a educação em tempos de pandemia. Canal do Saberes e Resistências no Youtube. Disponível em:

<https://www.youtube.com/watch?v=SEcZGLtLqB8\&list=PLAP4622d1ezCvmQOVqwWNYZ HeihwWPcDo\&index=4>. Acesso em: 5 mai. 2020.

NICODEMOS, Alessandra. Educação em tempos de pandemia. Canal Tarcísio Motta no Youtube. Disponível em : <https://www.youtube.com/watch?v=md-n16kw1vk\&t=344s $>$.

Acesso em: 10 mai. 2020.

OLIVEIRA, Fabiane Lopes de. Educação transformada em EAD durante a pandemia: quem e que está por trás dessa ação? In: AUGUSTO, C. B.; SANTOS, R. D. dos. Pandemias e pandemônio no Brasil. São Paulo: Tirant lo blanch, 2020. p. 247-260.

OLMO, Adela Mesa Del. ¿Nos convierte la COVID-19 en ciudadanos digitales? The conversation. Disponível em:<https://theconversation.com/nos-convierte-la-covid-19-enciudadanos-digitales-141541> Acesso em: 1 jul. 2020.

PREM, Kiesha et al. The effect of control strategies to reduce social mixing on outcomes of the COVID-19 epidemic in Wuhan, China: a modelling study. International Journal of Environmental Research and Public Health. v. 5, 2020. DOI:

https://doi.org/10.1016/S2468-2667(20)30073-6

REIS, Diego dos Santos. Coronavírus e desigualdades educacionais: reposicionando o debate. Olhar de professor, Ponta Grossa, v. 23, p. 1-5, 2020. Disponível em http://www.uepg.br/olhardeprofessor. Acesso em: 2 jul.2020.

SANTOS, Edméa. Ambientes virtuais de aprendizagem: por autorias livre, plurais e gratuitas. Revista FAEEBA, Salvador, v.12, n. 18, 2003.

SANTOS, Edméa. Pesquisa formação na cibercultura. Teresina:EDUFPI, 2019.

SANTOS, Edméa. EAD, palavra proibida. Educação online, pouca gente sabe o que é. Ensino remoto, o que temos para hoje. Mas qual é mesmo a diferença? \#livesdejunho... Revista Docência e Cibercultura, Rio de Janeiro, 21 jun. 2020. Disponível em: <https://www.epublicacoes.uerj.br/index.php/re-doc/announcement/view/1119>. Acesso em 20. jul. 2020.

SANTOS, Catarina de Almeida; PELLANDA, Andressa. COVID-19, o novo coronavírus- Guia 
sobre Educação a Distância. v.3, 2020. Disponível em :< https://campanha.org.br>. Acesso em 20 jul. 2020.

UNESCO. Resumen del Informe de Seguimiento de la Educación en el Mundo 2020: Inclusión y educación: todos sin excepción. París, UNESCO. 2020.

WANG, Cuiyan et al. Immediate psychological responses and associated factors during the initial stage of the 2019 Coronavirus Disease (COVID-19) epidemic among the general population in China. International Journal of Environmental Research and Public Health, 17(5), 1729, 2020. http://dx.doi.org/10.3390/ljerph17051729

ŽlŽEK, Slavoj. The appointment in samara: a new use for some old jokes. IN: TOSTES, A.; FILHO, H.M.(Orgs). Quarentena: reflexões sobre a pandemia e depois, 1.ed., Bauru: Canal 6, 2020.

ZUBILLAGA, Ainara; GORTAZAR, Lucas. Covid-19 y Educación: problemas, respuestas y escenarios. Documento técnico de análisis de la situación educativa derivada de la emergencia sanitaria. Fundación Cotec para la Innovación, 2020.

Recebido em: (07/08/2020)

Aceito em: (10/11/2020) 